\title{
I EL MODELO EDUCATIVO DE I LA UNIVERSIDAD DEL AZUAY
}

Francisco Salgado Arteaga y Martha Cobos Cali Rector y Vicerrectora Académica de la Universidad del Azuay

\section{El propósito del aprendizaje en la Universidad es formar ciudadanos que sean capaces de transformar el mundo.}

La educación superior significa formar y dignificar al ser humano en lo superior y para lo superior. Formar en lo superior implica contribuir al aprendizaje significativo con lo mejor del conocimiento y métodos científicos. Formar para lo superior supone una formación para el ejercicio de la ciudadanía con ética y estética: para hacer el bien con sensibilidad profunda.

La universidad es la sede de la razón y del corazón. La universidad está para el ejercicio de la razón sustantiva, aquella que permite entregarse con reciprocidad al servicio del otro y compartir con alegría el aprendizaje, la investigación y el servicio, por encima del cálculo utilitario de consecuencias, característica, esta, de la razón instrumental. A la razón debe complementarse el símbolo del corazón, la sensibilidad para hacer del campus un espacio de encuentro con uno mismo y con los otros. El modelo educativo de la Universidad del Azuay es de carácter humanista, de espíri- tu tolerante, abierto, flexible y libre, puesto al servicio de los demás.

Según Olmedo (2008) el pensamiento que precedió el nacimiento de la Universidad del Azuay integra:

a. Un profundo espíritu humanista, con matices ligados a la tradición cristiana.

b. Un profundo sentido y rigor académicos. Así desde su inicio tuvo raíces muy sólidas, que la prestigiaron y convirtieron, muy pronto, en un centro educativo atractivo, serio, responsable.

c. Un profundo espíritu pluralista: lo que se denomina pluralismo ideológico (filosófico, político, religioso, moral...). Su espíritu tolerante, abierto, flexible, libre, es un sello de su identidad. 
d. Un profundo sentido social, con su referente filosófico de personalismo (en el sentido de Mounier, Lacroix, Buber y otros), opuesto a los colectivismos y al individualismo. Así, la persona es el individuo, mas éste inserto en la comunidad. Persona y sociedad son conceptos complementarios. Para Mounier, además de libre, racional y afectiva, la persona es un ser social por naturaleza, que tiene como anverso de su unidad identificable e intransferible, su esencia social: fraternidad, libertad, solidaridad, responsabilidad con los demás.

En este pensamiento, resaltan como sus valores mas destacables, al igual que el de sus fundadores:

1. Un espíritu de sacrificio y desprendimiento económico.

2. Un profundo amor a la Institución y defensa apasionada de la misma. "Nada grande se ha hecho en el mundo sin una gran pasión", y

3. La perseverancia en los ideales y compromisos.

Así, comprendemos que la Universidad es una comunidad cuya misión es formar personas, desarrollar la ciencia y servir a la sociedad. En su esencia está el ser humano y su razón de ser es por y para el ser humano.

La Universidad es un espacio de encuentro en que todos los miembros de la comunidad se comprometen a acompañar y promover el aprendizaje. La Universidad se constituye así en comunidad de aprendizaje permanente: aprenden todos, desde el insigne pensador hasta el novel estudiante. Todos trabajamos juntos hacia el ideal de que todos los estudiantes que ingresen lleguen a graduarse oportunamente para realizarse a plenitud.

Realizarse a plenitud implica que la persona puede pensar con cabeza propia y actuar para hacer el bien, con sensibilidad para con los otros. Esta capacidad se fortalece en la Universidad con una formación que valore el aprendizaje autónomo, el pensamiento crítico y la innovación creativa. La presencia del estudiante con el profesor en el aula será la indispensable para contribuir a su autonomía, que se desarrolla en el laboratorio, en el taller, en el campo, en la biblioteca, y en otros espacios de aprendizaje en el que el estudiante es el protagonista. 
La asunción de riesgos es un atributo indispensable para la innovación y el emprendimiento. La oferta académica de la Universidad debe posibilitar que los estudiantes elijan un importante porcentaje de materias optativas para su formación. De esta manera se contribuye también a la formación del carácter y la responsabilidad del estudiante. Los bloques de materias obligatorias estarán en la base de la formación, mientras que, a medida que avance la carrera, se tendrán más bloques de materias optativas, con el fin de contribuir también a dar crédito al trabajo que realicen nuestros estudiantes en semestres académicos en el extranjero.

En este contexto, se propone poner al estudiante a la altura de su tiempo, a la altura del mundo. Esta perspectiva implica necesariamente vivir la internacionalización en la Universidad. Gracias a su visión pluralista, la inclusión de personas con diferentes culturas, la Universidad vivirá la diversidad tanto a nivel nacional como internacional. Ello iniciará con mayores niveles de tolerancia y escucha entre sus miembros, lo que permitirá ambientes cooperativos de trabajo, de redes académicas internacionales, que generen mayor bienestar y una alta movilidad de estudiantes y docentes con universidades de todo el mundo.

Por ello, la Universidad se propone ser un espacio en el que el inglés será su segunda lengua. La importancia del idioma inglés en el mundo académico es fundamental y por ello se priorizará una alta preparación de nuestros estudiantes y docentes en este idioma. A futuro se buscará la implementación de otros idiomas, de acuerdo con las necesidades, con el fin de abrir oportunidades de estudio y de trabajo para los graduados. Estos son requisitos sine qua non para vivir la internacionalización en la Universidad.

Todos los estudiantes que ingresan deben graduarse oportunamente: ese es el ideal al que todos debemos propender con nuestro trabajo de cooperación y reciprocidad. En los primeros niveles de las carreras se identificarán las materias que requieren de acompañamiento más cercano al estudiante, tanto en los aspectos académicos como en lo emocional, psicológico o espiritual. En la medida de lo posible, estas materias se ofrecerán todos los semestres, en horarios especiales, con el fin de que no se alargue innecesariamente la formación de la carrera. En los niveles intermedios y terminales de las carreras, la oferta de materias optativas permitirá reconocer el esfuerzo académico de los estu- 
diantes en el aprendizaje que ha sido elegido responsablemente, lo que contribuirá también a evitar que se cursen materias en tercera matrícula en los niveles más altos de la carrera. Es el esfuerzo académico el que se toma en cuenta para la promoción y la graduación, no una cadena de materias, cuyos métodos y contenidos están en constante cambio por el avance de la ciencia.

Estar a la altura del tiempo significa, además, estar en capacidad de comprender y utilizar las tecnologías de la información, que configuran nuevas oportunidades de aprendizaje a lo largo de la vida. La unidad de Universidad Abierta propiciará, como su objetivo fundamental, nuevos espacios y formas para aprender y compartir. Es indispensable complementar la formación presencial con la de los entornos virtuales, los cursos en línea, las redes académicas internacionales y el amplio acceso y uso de las bibliotecas y bases de datos científicas.

La comprensión del complejo contexto contemporáneo requiere de una perspectiva que permita abordar las situaciones desde su integralidad. Esta integralidad en la formación universitaria se aprovecha mejor con la oferta de cuerpos comunes de materias dentro y entre sus unidades académicas, lo que permite mayor movilidad interna de nuestros estudiantes y profesores. La Universidad del Azuay nace con su carrera en Humanidades, pero también se visualiza en las carreras técnicas, por lo que es legítimo hablar de humanismo técnico, implicando que todas las carreras tendrán formación humana y formación técnica (Olmedo, 2008). Esto le da un carácter de unidad e integralidad entre su oferta académica. La misma que en la actualidad incluye a postgrado y educación continua.

Se visualiza la formación de tercer nivel o de grado, como una un eslabón en la formación de los estudiantes, la misma que debe proporcionar conocimientos generales para que puedan afrontar nuevos retos de postgrados como maestrías o doctorados. Por ello es aconsejable ocupar al estudiante en el tiempo mínimo requerido para este nivel de formación. En nuestros días, el tiempo de formación de la licenciatura en Europa o Norteamérica está entre tres y cuatro años. Son los signos de los tiempos a los que debemos mirar con atención y actuar en consecuencia. 
Nuestro rigor académico integra a la evaluación como parte fundamental en el quehacer universitario, evaluación que permita medir tanto los resultados como los procesos que han estado implicados, y ayude a identificar las dificultades y /o amenazas para convertirlas en oportunidades. Esta evaluación debe rescatar del humanismo su carácter cualitativo.

La Universidad del Azuay es una de las primeras en establecer una unidad a nivel de vicerrectorado para la gestión de la investigación: ese nivel lo tuvo el Decanato General de Investigaciones en el estatuto original, que continúa con el Vicerrectorado de Investigaciones en el actual. Esto demuestra su interés en la innovación y la construcción del saber. Si bien existen diversos tipos de investigación, este proceso debe ser parte fundamental de la vida académica, desde los primeros niveles. A manera de retroalimentación, esto permite el fortalecimiento de grupos de investigación en las diferentes áreas del conocimiento. Junto con la vinculación, contribuyen decididamente a la transformación social.

Su esencia social: fraternidad, libertad, solidaridad, responsabilidad con los demás ha estado desde sus inicios, y la práctica no puede estar separada de la teoría; por ello la vinculación con la comunidad debe integrarse conjuntamente con la docencia y la investigación.

Para sostener e impulsar este pensamiento se fomentarán los valores de sacrificio y desprendimiento económico, la perseverancia y el reconocimiento a la parte afectiva "amor" o "pasión" hacia el ideal.

En síntesis, este modelo permite el desarrollo del ser humano, como un ser superior en beneficio del bien común, que es capaz de soñar, creer en ideales y utopías, y sorprendentemente, de hacerlas realidad. Como resalta nuestro himno de la Universidad del Azuay: "Más abierto que el cielo, abierto a las ideas, sin dogmas ni fronteras, abierto al pluralismo y a la diversidad". 
Nos damos el lujo de soñar:

Como dijera Hernán Malo: Es preciso soñar. Hay desacuerdo respecto al desacuerdo entre el sueño y la realidad. Mi sueño puede superar el curso natural de los acontecimientos..., el sueño no es nada insano; incluso puede sostener y reforzar la energía del trabajador... para emprender y llevar a término amplios y costosos trabajos en el campo de las artes, la ciencia y la vida cotidiana... El desacuerdo entre el sueño y la realidad nada tiene de nocivo, siempre y cuando el hombre que sueña crea seriamente en su sueño, observe atentamente la vida, compare sus observaciones con sus castillos de naipes y, de una manera general, trabaje concienzudamente en la realización de sus sueños. (Tomado de Paladines, 1986)

\section{Referencias}

Olmedo F., (2008). En torno al nacimiento de la Universidad-del Azuay. Universidad Verdad. No. 46. Revista de la Universidad del Azuay.

Paladines C., (1986). Los sueños de Hernán Malo. Universidad-Verdad, No. 1: Revista de la Pontificia Universidad Católica del Ecuador, sede en Cuenca. 


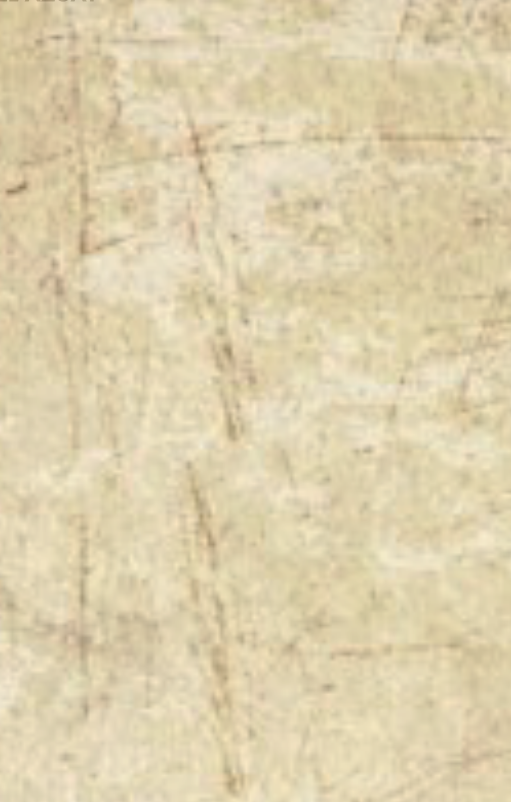

